\title{
Efficiency in Second-Price Auctions: A New Look at Old Data
}

\author{
Rodney J. Garratt • John Wooders
}

(C) The Author(s) 2010. This article is published with open access at Springerlink.com

\begin{abstract}
Experiments on second-price sealed-bid private value auctions have established that subjects typically bid more than their value, despite the fact that value bidding is a dominant strategy in such auctions. Moreover, the laboratory evidence shows that subjects do not learn to bid their values as they gain more experience. In the present paper, we re-examine the second-price auction data from Kagel and Levin's (Econ J 103:868-879, 1993) classic paper. We find that auction efficiency increases over time, even though the frequency of overbidding is unchanged. We argue that the rise in efficiency is due to a decline in the variability of overbidding. This is consistent with subjects' learning to bid more like each other.
\end{abstract}

Keywords Bidding $\cdot$ Efficiency $\cdot$ Second price auction

\section{Introduction}

In a second-price sealed-bid auction with private values, the highest bidder wins the auction and pays the second highest bid. In such auctions, it is a dominant strategy for

The present paper is based on Garratt and Wooders (2004). We are grateful to John Kagel for providing us with data from experiments reported in Kagel and Levin (1993). We thank Dan Ackerberg, Victor Tremblay, and two anonymous referees for helpful comments.

\section{R. J. Garratt}

Department of Economics, University of California, Santa Barbara, CA 93106, USA

e-mail: garratt@econ.ucsb.edu

J. Wooders (凶)

Department of Economics, McClelland Hall, Tucson, AZ 85721, USA

e-mail: jwooders@eller.arizona.edu 
a bidder to bid his value. ${ }^{1}$ One of the striking results to come from the experimental literature on second price auctions (SPAs) is that subjects have a strong tendency to bid more than their value. In 5-bidder auctions, for example, Kagel and Levin (1993) find that over two-thirds of all bids exceed the bidder's value. Kagel et al. (1987) find that the market price (the second highest bid) exceeds the second highest value in $80 \%$ of their SPAs. Further evidence of overbidding is reported in Harstad (2000).

These papers report, moreover, that there is little evidence that subjects learn to bid their values. Kagel and Levin (1993) note that: "Learning to play the dominant strategy is quite limited as only 2 out of 21 subjects play it precisely for 5 or more consecutive periods starting from the end of the auction series." 2 Kagel et al. (1987) report "... no obvious tendency for prices to converge to the dominant bid price over time was observed." 3

In the present paper we re-examine the data from Kagel and Levin (1993). We show that there is a strong tendency for auction efficiency to rise over time. In particular, by the end of their experiment, the second-price auction assigns the item to the bidder with the highest value with probability .95 or higher. Even when the item is misallocated, the surplus lost tends to be small, with the auction capturing, on average, nearly $99 \%$ of the theoretical surplus. Hence, even though bidding is not converging to value bidding, as subjects gain experience SPAs perform remarkably well. In particular, bidding behavior changes over time, in a way that leads to higher efficiency.

Our measures of auction efficiency use a technique known as recombinant estimation. ${ }^{4}$ We begin by first forming the empirical distribution of bid-value pairs. (For each period there are 20 such pairs for Kagel and Levin's second-price auctions.) We then consider all possible groups of five bidders and the corresponding five bid-value pairs and, for each group, we compute whether the bidder with the highest bid also has the highest value. The fraction of groups for which the highest bidder has the highest value is our measure of the probability that the bidder with the highest value wins.

This technique is closely related to a statistical technique known as bootstrapping (Efron and Tibshirani 1993). In our context, bootstrapping would involve repeatedly drawing random groups of five bidders, with replacement, and computing average efficiency from the realized groups. The approach we use involves sampling without replacement. In addition, using techniques described in Bergstrom et al. (2009), we are able to compute estimates that are based on all possible combinations. This is referred to as exact recombination and is analogous to ideal bootstrapping. Exact recombination produces an unbiased estimate and is appropriate for making an inference about the sample population. For further discussion see Bergstrom et al. (2009).

One could, of course, simply measure efficiency in the Kagel and Levin data based on the four groups of five bidders that actually formed in the experiment. Such an approach seems unnatural given that bidders are randomly assigned to groups.

\footnotetext{
1 In other words, a bidder's payoff to placing a bid equal to his value for the item is at least as great as his payoff to placing any other bid, regardless of the other bids submitted.

2 See Kagel and Levin (1993, p. 872, fn. 5).

3 See Kagel and Roth (1995, ch. 5) for a survey of the experimental literature on auctions.

4 Mitzkewitz and Nagel (1993) and Mehta et al. (1994) use recombinant estimation on data from bargaining and coordination games, respectively.
} 
Table 1 Kagel and Levin (1993) Second Price Auctions

\begin{tabular}{llll}
\hline $\begin{array}{l}\text { Auction } \\
\text { session }\end{array}$ & $\begin{array}{l}\text { Number of } \\
\text { Subjects }\end{array}$ & $\begin{array}{l}\text { Bidders per } \\
\text { Auction }\end{array}$ & $\begin{array}{l}\text { Auction } \\
\text { Periods }\end{array}$ \\
\hline 2.1 & 10 & 5 & $1-12$ \\
2.2 & 10 & 5 and 10 & $13-24$ \\
& 5 & 10 & $1-13$ \\
& & 5 & $14-25$ \\
\hline
\end{tabular}

Furthermore, recombinant estimation produces an estimate of efficiency that has a lower standard error, in a sense made precise in Mullin and Reiley (2006), than the estimate that is based on the groups actually formed during the experiment to determine payoffs.

We argue that the explanation for rising efficiency is that the variance of overbids falls over time. ${ }^{5}$ Hence, even though bidders continue to overbid, the bidder with the highest value becomes increasingly likely to have the highest bid. A falling variance in overbids is consistent with bidders tending to all overbid by a similar amount- they learn to bid more like each other.

\section{Kagel and Levin's Data on Second-Price Auctions}

Our analysis is based on the second-price auction experiments reported in Kagel and Levin (1993). ${ }^{6}$ Each experiment had ten subjects. In each period, each subject's value was randomly drawn from the uniform distribution on $\$ 0$ to $\$ 28.30$. The subjects then participated in a second-price sealed-bid auction in a market with either five or ten bidders. After each auction, subjects observed the bids and values of the other subjects in their group, along with the profit (or loss) of the winner. Any profits (losses) were added to (subtracted from) the subject's current cash balance. Subjects were given an initial cash balance of $\$ 10$. A subject who went bankrupt in the course of the experiment was removed.

The experimental design for the second-price auctions is summarized in Table 1 above. Periods 13-24 of session 2.1 used a "dual market" procedure in which, using the same value, a subject simultaneously bid in a market with five bidders and a market with ten bidders. Session 2.2 used a "cross over" procedure in which subjects first bid in a market with five bidders, and then bid in market with ten bidders.

We use the data from the five-bidder auctions. More specifically, we pooled, period by period, the first 23 periods of bids in the five-bidder markets of Sessions 2.1 with the 23 periods (1-13 and 26-35) of bids from five-bidder markets of Session 2.2. (The bids from period 24 of Session 2.1 are dropped since they have no counterpart in Session 2.2.) This gives us 23 periods of data with 20 observations per period. One could, of

\footnotetext{
5 Remember that efficiency does not require "value-bidding." Everyone overbidding (or underbidding) by the same amount also yields efficient allocations.

6 Kagel and Levin (1993) also report results from first- and third-price auctions, but here we restrict attention to second-price auctions.
} 


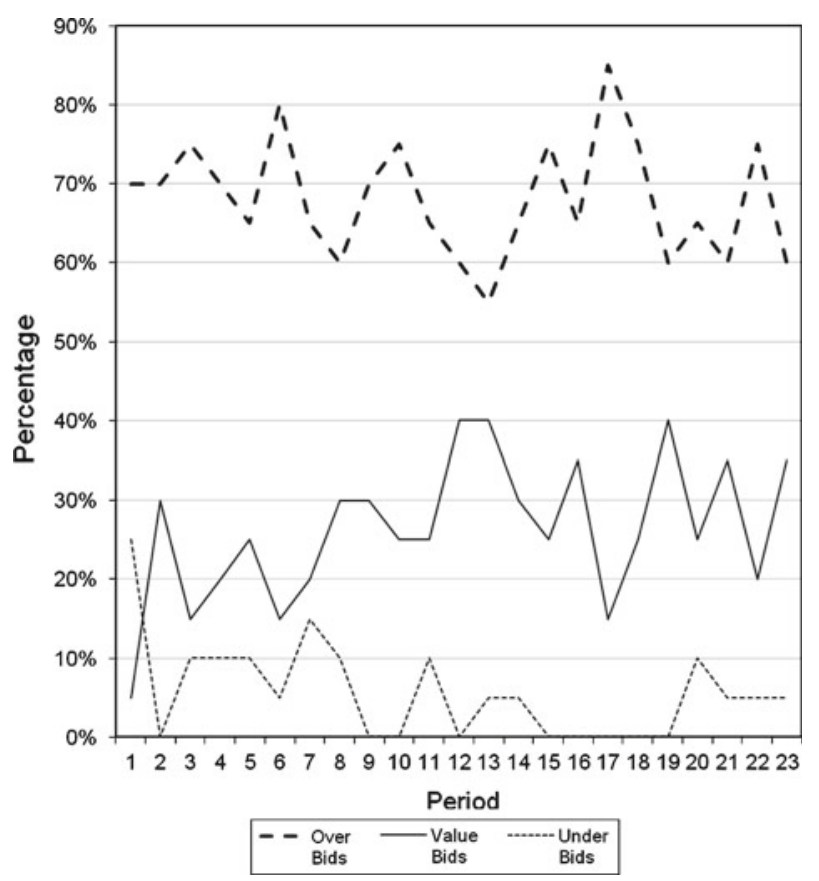

Fig. 1 Frequency of under-, value-, and over-bids in the five bidder markets of Sessions 2.1 and 2.2.

course, analyze the data from Sessions 2.1 and 2.2 separately, rather than pooling the data. However, such an approach would diminish the value of recombinant estimation, increasing the standard error of the efficiency estimates, and obscuring any time trends in efficiency. Since there is a limited amount of data for ten-bidder auctions, we ignore these auctions.

$\mathrm{K} \& \mathrm{~L}$ documented that there was (1) a strong tendency for subjects to bid above their values, with nearly two-thirds of all bids being overbids, and there was (2) no tendency for subjects to learn to bid their values over time. Figure 1 illustrates these conclusions by showing the frequency of "under bids," "value bids," and "over bids" across time. Here, as in K\&L, a bid is classified as an overbid if it is more that 5 cents above the bidder's value, it is an underbid if it is more than 5 cents below his value, and it is a value bid otherwise.

$\mathrm{K} \& \mathrm{~L}$ convincingly argue that the lack of convergence towards value bidding is a result of the weak learning incentives in second-price auctions. They report for the five-bidder market that, conditional on winning the auction, a subject lost money only one-quarter of the time. Hence, subjects generally made money when they won, whether they had overbid or not.

\section{Convergence to Efficiency}

Figure 1 shows that subjects do not learn to value bid, at least as K\&L defined it. However, examining auction efficiency reveals that subjects are bidding differently 


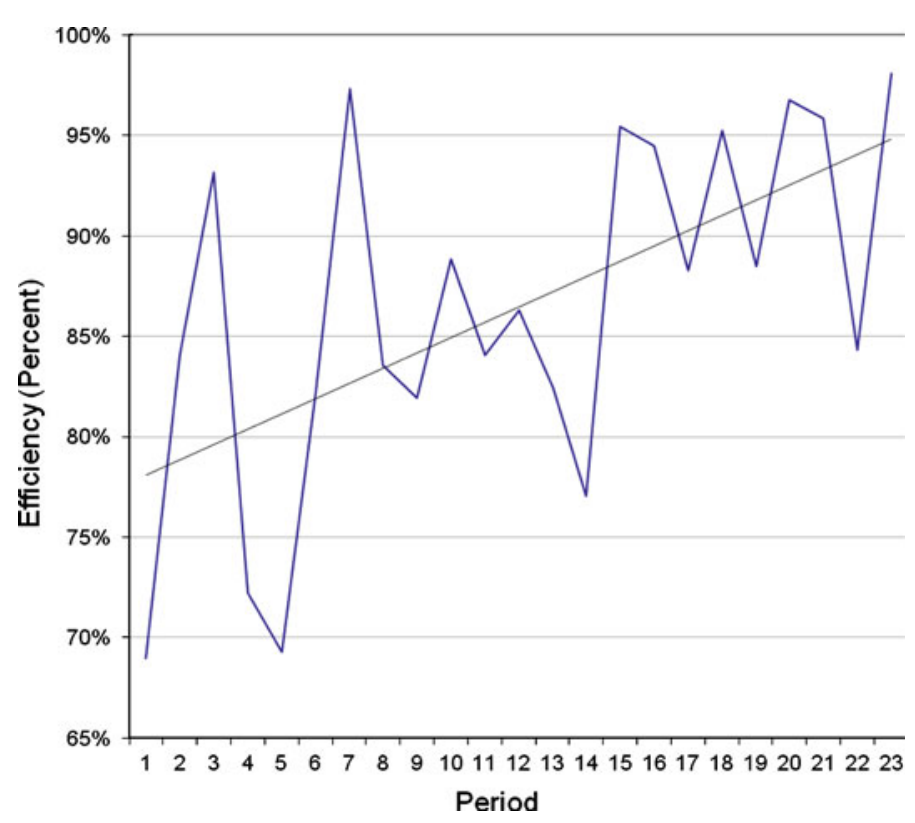

Fig. 2 Efficiency over time in K\&L's five-bidder auctions

over time. Our measure of efficiency applies to an empirical distribution of bid-value pairs. Consider a sample of $n$ bid-value pairs that are formed by pairing the bid of each of $n$ subjects with the subject's value. Given this sample, auction efficiency in a market with $k$ bidders is defined to be the probability that, in a random sample of $k$ of the $n$ bid-value pairs, the highest of the $k$ bids is paired with the highest of the $k$ values. It represents the probability that the auction is efficient (i.e., the bidder with the highest value wins), when bidding behavior is described by the empirical distribution of bid-value pairs. An equivalent way to think of this efficiency measure is that it represents the fraction of the

$$
J=\frac{n !}{k !(n-k) !}
$$

possible different groups of $k$ bidders that, if formed, would yield an efficient outcome given their bids and values.

K\&L's data for markets with five bidders provide, for each of the 23 periods, an empirical distribution of 20 bid-value pairs. Figure 2 plots auction efficiency, as defined above, in a market with five bidders across the 23 periods. It is visually apparent that efficiency tends to rise over time. In a regression of efficiency against time (see Column (a) of Table 2), the estimated slope of .008 is statistically significant ( $p$-value of .002 ), and suggests that efficiency rises by approximately $.8 \%$ each period. (The fitted regression line is also shown in Fig. 2).

An alternative, but related, measure of efficiency is expected lost surplus. Expected lost surplus is the expected difference between the highest bidder's value and the 
Table 2 Regression Results

\begin{tabular}{llll}
\hline Dependent Variable & Efficiency (a) & Overbid (b) & Squared Residuals from (b) (c) \\
\hline Constant & $0.773(0.031)^{* *}$ & $1.295(0.172)^{* *}$ & $6.632(1.424)^{* *}$ \\
Period & $0.008(0.002)^{* *}$ & $-0.027(0.013)^{*}$ & $-0.289(0.104)^{* *}$ \\
Observations & 23 & 457 & 457 \\
R squared & 0.3130 & 0.0100 & 0.0174 \\
Adj. R squared & 0.0729 & 0.0078 & 0.0152 \\
\hline
\end{tabular}

Standard errors are in parenthesis. $* *$ and $*$ denote significance at the $1 \%$ and $5 \%$ level, respectively.

highest value, in a random sample of five of the 20 bid-value pairs. It measures how much surplus is lost, on average, as a result of the item being allocated inefficiently. Once again, consider forming the $J=20$ !/[5! $(20-5)$ ! ] possible groups of five bidders out of 20 bidders in each period, and index the different groups by $j$. For each group $j(j=1, \ldots, J)$ let $v_{j}^{*}$ denote the highest value of a bidder in group $j$, and let $v_{j}^{* *}$ denote the value of the bidder with the highest bid in group $j$. Expected lost surplus for each period is given by

$$
\frac{1}{J} \sum_{j=1}^{J}\left(v_{j}^{*}-v_{j}^{* *}\right) .
$$

Figure 3 shows that expected lost surplus (measured on the left-vertical axis) falls quite quickly. In the first third, second third, and last third of the experiment the average expected loss is $\$ .67, \$ .25$, and $\$ .08$. Hence, the expected loss from inefficient allocations becomes small.

The right-vertical axis of Fig. 3 shows the (expected) surplus captured as a percentage of total surplus. This is defined by

$$
\frac{1}{J} \sum_{j=1}^{J} \frac{v_{j}^{*}-v_{j}^{* *}}{v_{j}^{*}},
$$

and it is essentially above $99 \%$ over the last third of the experiment. Figure 3 shows that by the last third of the experiment the second-price sealed-bid auction is performing well, losing only a small amount of surplus in absolute terms, and capturing nearly all surplus in percentage terms. It shows that the failure over time of subjects to bid their dominant strategy largely does not undermine the theoretical efficiency of the second-price auction.

\section{Understanding Rising Efficiency}

While subjects do not learn to value bid, Figs. 2 and 3 demonstrate that auction efficiency and the percentage of surplus captured are both rising, while expected lost surplus falls. In this section we investigate the changes in bidding behavior that explain 


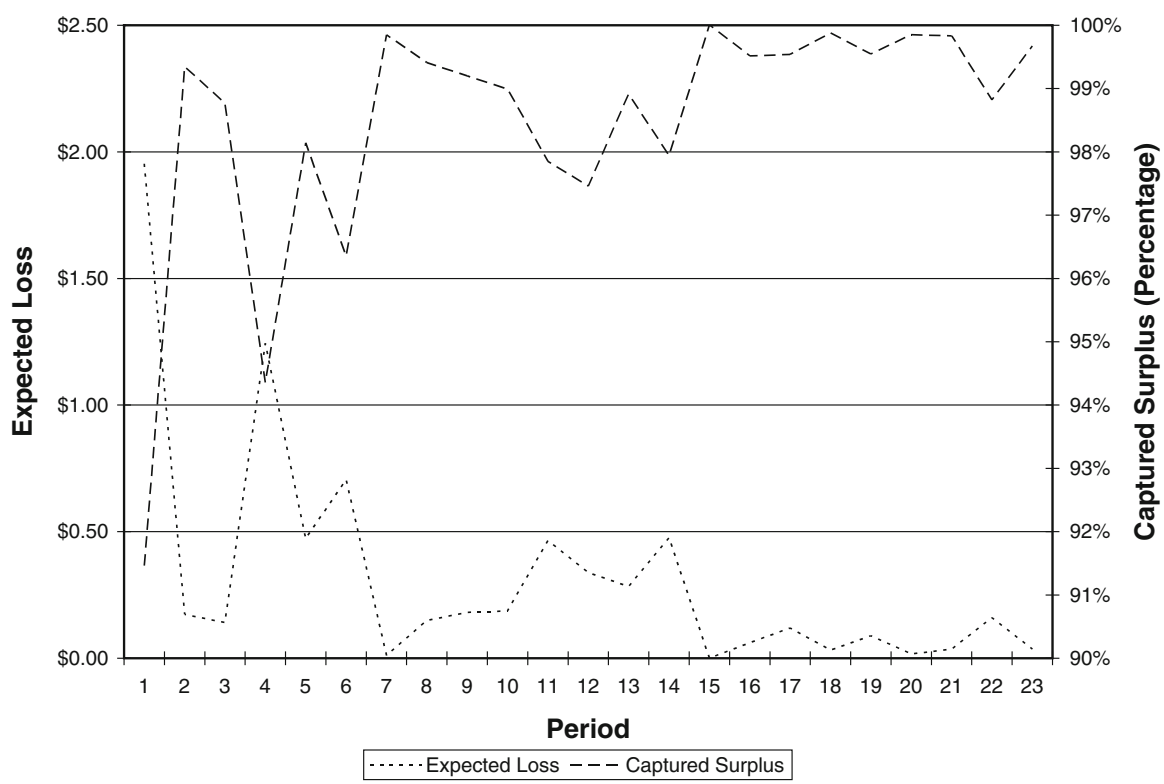

Fig. 3 Expected lost surplus in K\&L's five-bidder auctions

these trends. In our analysis of the data we drop three very large overbids, made by the same subject. Including them would have a large effect on the regression results since each of these overbids is more than $\$ 26$, while the mean absolute deviation from value bidding (excluding these overbids) is $\$ 1.30$ overall. Since the subject had high values when making these overbids, dropping them has little effect on the efficiency statistics displayed in Figs. 2 and 3. ${ }^{7}$

The first feature of the data is that there is a small tendency for the mean overbid to decline over time. Column (b) of Table 2 reports the results of regressing overbids against time. It shows that overbids decrease by about 2.7 cents per period, and this effect is statistically significant. Declining overbids, however, do not explain rising efficiency. If, for example, every subject overbid by the same amount, then efficiency would be 1, and constant across time, even if the amount of the overbid were falling over time.

More insight into rising efficiency can be obtained by examining the squared residuals of the regression from (b). The squared residuals are a measure of the variance of overbids, under the hypothesis that the mean overbid is declining according to the regression results that are reported in (b). Column (c) of Table 2 shows that the squared residuals, and hence the variance of overbids, are falling over time, and this effect is statistically significant. The auction allocation is inefficient when the bidder with the highest value doesn't have the highest bid. This becomes less likely as the variance of

\footnotetext{
7 The three dropped bids (in periods 14, 16, and 17) were all of exactly $\$ 55.00$. Efficiency in these periods was, respectively, .77, .94, and .88. Excluding these bids yields efficiencies of .82, .93, and .97, respectively.
} 
overbids falls, and hence the decline in the variance of overbids explains the rise in auction efficiency.

\section{Concluding Remarks}

The seller of an item may be interested in seeing that the item is allocated efficiently i.e., that the bidder who values the item most highly wins it. In government auctions of radio frequency spectrum or auctions of rights to drill for oil, for example, allocative efficiency may be of greater interest than revenue maximization. The results we report here suggest that despite the failure of subjects to follow their dominant strategy of bidding their values, second-price sealed-bid auctions nonetheless yield highly efficient outcomes.

Moreover, we have discovered a previously unrecognized feature of Kagel and Levin's second-price auction data: auction efficiency in a second-price sealed-bid auction rises over time. The explanation for this phenomenon appears to be that while bidders in second-price auctions do not learn to bid optimally over time, they do learn to bid more like each other. It is the reduction in the variability of overbids that leads to increased efficiency. Our findings call for further research into the robustness of learning and rising efficiency in second-price auctions.

Open Access This article is distributed under the terms of the Creative Commons Attribution Noncommercial License which permits any noncommercial use, distribution, and reproduction in any medium, provided the original author(s) and source are credited.

\section{References}

Bergstrom, C., Bergstrom, T., \& Garratt, R. (2009). Ideal bootstrapping and exact recombination: Applications to auction experiments, UC Santa Barbara: Department of Economics. Retrieved from: http://escholarship.org/uc/item/4xb7454q.

Efron, B., \& Tibshirani, R. (1993). An introduction to the bootstrap. New York: Chapman and Hall.

Garratt, R., \& Wooders, J. (2004). Efficiency in second-price auctions: A new look at old data. University of California at Santa Barbara working paper 02-04.

Harstad, R. (2000). Dominant strategy adoption and bidders experience with price rules. Experimental Economics, 3, 261-280.

Kagel, J., Harstad, R., \& Levin, D. (1987). Information impact and allocation rules in auctions with affiliated private values: A laboratory study. Econometrica, 55, 1275-1304.

Kagel, J., \& Levin, D. (1993). Independent private value auctions: Bidder behavior in first-, secondand third-price auctions with varying numbers of bidders. Economic Journal, 103, 868-879.

Kagel, J., \& Roth, A. (1995). Handbook of experimental economics. Princeton: Princeton University Press.

Mehta, J., Starmer, C., \& Sugden, R. (1994). The nature of salience: An experimental investigation of pure coordination games. American Economic Review, 84, 658-673.

Mitzkewitz, M., \& Nagel, R. (1993). Experimental results on ultimatum games with incomplete information. International Journal of Game Theory, 22, 171-198.

Mullin, C. H., \& Reiley, D. H. (2006). Recombinant estimation for normal-form games, with applications to auctions and bargaining. Games and Economic Behavior, 54, 159-182. 